\title{
Climate intercomparison of GPS radio occultation, RS90/92 radiosondes and GRUAN from 2002 to 2013
}

\author{
F. Ladstädter ${ }^{1}$, A. K. Steiner ${ }^{1}$, M. Schwärz ${ }^{1}$, and G. Kirchengast ${ }^{1,2}$ \\ ${ }^{1}$ Wegener Center for Climate and Global Change (WEGC), University of Graz, Graz, Austria \\ ${ }^{2}$ Institute for Geophysics, Astrophysics, and Meteorology/Institute of Physics, University of Graz, Graz, Austria \\ Correspondence to: F. Ladstädter (florian.ladstaedter@uni-graz.at)
}

Received: 31 October 2014 - Published in Atmos. Meas. Tech. Discuss.: 25 November 2014

Revised: 18 March 2015 - Accepted: 1 April 2015 - Published: 23 April 2015

\begin{abstract}
Observations from the GPS radio occultation (GPSRO) satellite technique and from the newly established GCOS Reference Upper Air Network (GRUAN) are both candidates to serve as reference observations in the Global Climate Observing System (GCOS). Such reference observations are key to decrease existing uncertainties in upperair climate research. There are now more than 12 years of data available from GPSRO, with the recognized properties high accuracy, global coverage, high vertical resolution, and long-term stability. These properties make GPSRO a suitable choice for comparison studies with other upper-air observational systems. The GRUAN network consists of reference radiosonde ground stations (16 at present), which adhere to the GCOS climate monitoring principles. In this study, we intercompare GPSRO temperature and humidity profiles and Vaisala RS90/92 data from the "standard" global radiosonde network over the whole 2002 to 2013 time frame. Additionally, we include the first years of GRUAN data (using Vaisala RS92), available since 2009. GPSRO profiles which occur within $3 \mathrm{~h}$ and $300 \mathrm{~km}$ of radiosonde launches are used. Overall very good agreement is found between all three data sets with temperature differences usually less than $0.2 \mathrm{~K}$. In the stratosphere above $30 \mathrm{hPa}$, temperature differences are larger but still within $0.5 \mathrm{~K}$. Day/night comparisons with GRUAN data reveal small deviations likely related to a warm bias of the radiosonde data at high altitudes, but also residual errors from the GPSRO retrieval process might play a role. Vaisala RS90/92 specific humidity exhibits a dry bias of up to $40 \%$ in the upper troposphere, with a smaller bias at lower altitudes within $15 \%$. GRUAN shows a marked improvement in the bias characteristics, with less than $5 \%$ difference to GPSRO, up to $300 \mathrm{hPa}$. GPSRO dry temperature and physi-
\end{abstract}

cal temperature are validated using radiosonde data as reference. We find that GPSRO provides valuable long-term stable reference observations with well-defined error characteristics for climate applications and for anchoring other upperair measurements.

\section{Introduction}

Uncertainties in upper-air observations are still an issue. The latest assessment report of the Intergovernmental Panel on Climate Change (IPCC) states about the troposphere and stratosphere that "despite unanimous agreement on the sign of the trends, substantial disagreement exists among available estimates as to the rate of temperature changes... Hence there is only medium confidence in the rate of change and its vertical structure in the $\mathrm{NH}$ extratropical troposphere and low confidence elsewhere." (IPCC, 2013). While trends in surface temperature from different data sources are in close accordance, the challenges related to maintaining a homogeneous upper-air time series of temperature, water vapor and other atmospheric parameters are more demanding.

Upper-air measurements from radiosondes have long been the primary source of information, with measurements going back more than 60 years, and efforts to establish a standardized global network commenced 1958. These measurements are unique with regard to the length of the available time series as well as with their high vertical resolution. Nevertheless there are substantial difficulties in how to interpret the data for climate studies due to a large number of different radiosonde types with varying error characteristics and insufficient documentation (Luers and Eskridge, 1998). 
Radiosondes are known to suffer from radiation biases in temperature and humidity measurements, and there have been many attempts to quantify or correct these biases (e.g., Sun et al., 2013; J. Wang et al., 2013; Haimberger et al., 2008, 2012; Ho et al., 2010; Titchner et al., 2009; Vömel et al., 2007; Miloshevich et al., 2006; Luers and Eskridge, 1998). Most sonde types include their own correction schemes which are applied at the ground station before the data are transmitted. The version of corrections used at a specific sounding or the date of software updates to newer versions are usually unknown. Also the algorithms used by the vendors are commonly proprietary, making adherence to the principle of fully traceable and openly documented algorithms difficult.

These challenges point to the need for additional data sets of reference quality in order to better account for measurement biases, and to be able to estimate the structural uncertainty involved. Such structural uncertainty inevitably arises from differences in the chosen approaches, and is decreased by increasing the number of data sets (Thorne et al., 2011a, 2005; Santer et al., 2008; Karl et al., 2006). As a reaction to the need for a systematic approach to climate observations, WMO's Global Climate Observing System (GCOS) was founded in 1992 (GCOS, 2010). One particular output of the GCOS effort is the establishment of the GCOS Reference Upper Air Network (GRUAN) as an international reference observing network of upper-air measurements (Seidel et al., 2009).

The GRUAN network is envisioned to consist of $30-40$ ground stations providing reference measurements which adhere to the climate monitoring principles stated by GCOS (Immler et al., 2010). At present (spring 2015), 4 stations are certified GRUAN stations and 11 more are candidate stations. Since GRUAN will not provide observations with global coverage, it is not thought as a replacement of the existing network of radiosonde stations, but rather as a key component in the GCOS system to anchor existing observations and to facilitate their transformation to climate data records. The complete network of radiosonde stations is also limited in the sense that it predominately covers land regions and has poor coverage of the Southern Hemisphere.

Satellite measurements can come to the rescue here. Upper-air temperature measurements from satellites exist primarily from the (Advanced) Microwave Sounding Unit ((A)MSU) instrument flying on US National Oceanic and Atmospheric Administration (NOAA) polar orbiting satellites (since 1979). (A)MSU observations have complete global coverage, but they also suffer from substantial uncertainties due to inter-satellite offsets and diurnal drift biases. Despite immense efforts to calibrate and homogenize these upper-air data, the long-term climate trends in troposphere and stratosphere are still subject to controversy (Wang and Zou, 2014; IPCC, 2013; Thorne et al., 2011b; Ladstädter et al., 2011; Randel et al., 2009; Zou and Wang, 2009; Mears and Wentz, 2008; Steiner et al., 2007).
A technique combining the advantages of global coverage of satellite measurements with high quality, SI-traceability, and long-term stability is Global Positioning System (GPS) radio occultation (RO) (GPSRO) (Anthes, 2011).

It is identified by GCOS as another of its key components (GCOS, 2011), and is currently the only self-calibrated and SI-traceable satellite-based measurement system (Leroy et al., 2006). The key observed quantity is the excess phase of GPS signals propagating through Earth's atmosphere and can therefore be traced back to a precise time measurement.

Since measurements are performed in limb geometry, the horizontal footprint of about 60 to $300 \mathrm{~km}$ along-ray and $1.5 \mathrm{~km}$ across-ray (Melbourne et al., 1994; Kursinski et al., 1997 ) is coarse in comparison to radiosonde point-like measurements. The vertical resolution varies with altitude and ranges from about $100 \mathrm{~m}$ in the lower troposphere (Gorbunov et al., 2004) to about $1 \mathrm{~km}$ in the stratosphere (Kursinski et al., 1997).

Data from different GPSRO missions can be combined without inter-calibration factors (Steiner et al., 2013; Foelsche et al., 2011). The value of GPSRO to act as a reference measurement with climate quality has been demonstrated in a range of publications, including GPSRO comparisons with (A)MSU and radiosonde data (e.g., Sun et al., 2010, 2013; B.-R. Wang et al., 2013; Ladstädter et al., 2011; Ho et al., 2007, 2010; He et al., 2009; Steiner et al., 2007; Kuo et al., 2005). These characteristics underpin its value to act as an upper-air reference observation system with global coverage.

In this study we use GPSRO profiles from three different missions from 2002 to 2013 in order to rigorously intercompare them with data from the commonly used high-quality radiosonde type Vaisala RS90/92 on a global scale. In addition, we use GPSRO data to intercompare temperature and humidity observations with collocated profiles from the GRUAN data record over 2009 to 2013.

\section{Data and methodology}

\subsection{GPS radio occultation data}

We use data from three GPS radio occultation (GPSRO) missions: CHAMP (Wickert et al., 2001) data are used from December 2001 to September 2008, GRACE-A (Beyerle et al., 2005) data from March 2007 to December 2013, and FORMOSAT-3/COSMIC (F3C) (Anthes et al., 2008) from August 2006 to December 2013. The number of GPSRO profiles greatly increased with the launch of the $\mathrm{F} 3 \mathrm{C}$ mission (by approximately a factor of 10 ). The full study period is therefore December 2001 to December 2013, covering more than 12 years.

All data were consistently processed with Wegener Center for Climate and Global Change's (WEGC) OPSv5.6 processing system using excess phase data from the COSMIC Data Analysis and Archiving Center (CDAAC) at University 
Corporation for Atmospheric Research (UCAR) in Boulder, Colorado. In the GPSRO retrieval process, the excess phase changes sampled during the occultation event while the GPS signals scan through the atmosphere, are transformed into bending angle profiles and onward to refractivity profiles. The relation between refractivity $(N)$ and atmospheric pressure, temperature, and water vapor pressure is then given by the Smith-Weintraub formula (Smith and Weintraub, 1953). Neglecting moisture in this formula leads to the so-called "dry-air" retrieval (Kursinski et al., 1997), which is valid in the dry atmosphere above the mid- to upper troposphere. The dry temperature obtained in this retrieval is always less than the physical, actual temperature. In dry-air conditions with negligible water vapor concentration, physical and dry parameters are equivalent. A detailed explanation of dry and physical GPSRO parameters and their quantitative relationship is given by Scherllin-Pirscher et al. (2011a).

In order to obtain physical parameters from GPSRO, additional background information must be included. In the OPSv5.6 processing, an optimal estimation retrieval is applied for the purpose. Here we use collocated European Centre for Medium-Range Weather Forecasts (ECMWF) shortrange forecast profiles as background. The optimal estimation is applied up to an altitude of $16 \mathrm{~km}$, with a half-sineweighted transition from physical to dry parameters between 14 and $16 \mathrm{~km}$ for temperature and pressure. This signifies that at $14 \mathrm{~km}$ and below, only information from the optimal estimation retrieval enters the profiles, while at $16 \mathrm{~km}$ and above, physical and dry parameters are identical to within $0.01 \mathrm{~K}$ (the physical temperature being only very slightly larger due to stratospheric water vapor). In this study, we primarily use physical parameters but also include a specific validation of dry and physical temperatures against radiosonde data.

In this intercomparison, we only use GPSRO profiles which passed the OPSv5.6 quality control (these amount to approximately $70 \%$ of all profiles), which includes plausibility checks for bending angle, refractivity, and temperature profiles. For details on the OPSv5.6 processing, dry/moist retrieval, and quality control, please refer to Schwärz et al. (2013); the processing closely builds on the OPSv5.4 predecessor processing described as part of Steiner et al. (2013) and Ho et al. (2012).

Error characteristics for GPSRO parameters are provided from empirical error estimation. Empirical-analytical error models for individual profiles and for climatologies are available (Scherllin-Pirscher et al., 2011a, b). For temperature, the observational root-mean-square (RMS) error for individual GPSRO profiles is estimated to be 0.7 to $1.0 \mathrm{~K}$ within 8 to $25 \mathrm{~km}$ for current missions (Scherllin-Pirscher et al., 2011b). The statistical observational error from averaging over hundreds of profiles becomes then very small $(<0.01$ to $0.1 \mathrm{~K})$. Systematic errors are estimated to be $<0.2 \mathrm{~K}$ below $25 \mathrm{~km}$ due to potential downward-propagated residual ionospheric biases, high-altitude initialization of bending angles, resid- ual representativeness errors, and refractivity coefficient errors (Scherllin-Pirscher et al., 2011a).

To sum up, the overall uncertainty bound for a sample of 100 GPSRO or more profiles, including the statistical observational and the systematic errors, is generally $<0.3 \mathrm{~K}$ within 8 to $25 \mathrm{~km}$ and stays $<0.8 \mathrm{~K}$ up to $35 \mathrm{~km}$ and down to $5 \mathrm{~km}$ (Schwärz et al., 2013). A detailed review of the main characteristics of GPSRO is given by Steiner et al. (2011).

\subsection{Vaisala RS90/92 radiosonde data, including GRUAN}

Radiosonde data used in this study are obtained from two sources: the ECMWF ERA-Interim observation archive, which contains radiosonde data transmitted by the Global Telecommunication System (GTS), and the RS92 GRUAN data product (RS92-GDP) version 2 (www.gruan.org). We limit the comparison to the usage of two Vaisala radiosonde types, RS90 and RS92, considered to be of highest quality (Nash et al., 2011) and therefore qualified to support the focus of this study as a first-time rigorous climatological intercomparison of thermodynamic upper-air reference data. Vaisala RS90 was introduced in 1997 and is included in our study for comparisons in the years before RS92 had reached a good global coverage. RS92, introduced in 2003, has been increasingly in use around the world. It has similar temperature and humidity sensors as RS90.

The radiosonde data from the ERA-Interim archive (denoted RS in this study) include all mandatory and significant levels reported by the GTS. The RS profiles used here have a mean vertical step size of approximately $350 \mathrm{~m}$. From the distribution map plot in Fig. 1, representative for the first years of the study time frame, it is evident that most data were available from Vaisala RS90 launches over Europe. In 2011, shown in Fig. 2 and representative for the time period since 2006, most data came from Vaisala RS92 with a much better global distribution. Notable coverage gaps can be seen over large parts of Asia, Africa, and the USA. Measurements are very sparse over the oceans.

We process and check the RS profiles individually in order to ensure a comparable quality. We reject each profile which contains overly large vertical gaps between adjacent levels in a defined "core region" of 600 to $200 \mathrm{hPa}$ (about 4 to $12 \mathrm{~km}$ ), with a maximum allowed inter-level gap of $2000 \mathrm{~m}$ for temperature and of $4000 \mathrm{~m}$ for humidity. If the humidity profile is rejected according to these criteria, but the temperature profile passes, we keep the temperature profile for further processing. A minimum of 8 pressure levels in the core region is required. The profiles are cut outside the core region at the occurrence of the first large gap (defined as before), separately for temperature and humidity. This causes a distinct decrease in sample size above $200 \mathrm{hPa}$, visible in all RS comparisons.

For profiles fulfilling these conditions, occasionally missing temperature and relative humidity values are interpo- 


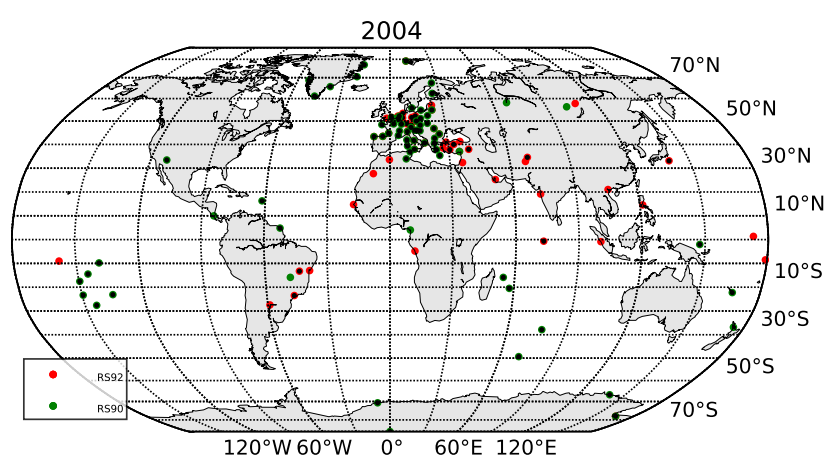

Figure 1. Map of geographic distribution of radiosonde launch stations in 2004. Stations with launches of Vaisala RS90 are marked in green, those launching Vaisala RS92 in red. If there were collocations with GPSRO profiles at a station it is marked with a black dot.

lated linearly on the logarithmic pressure grid. Finally, missing specific humidity values are calculated from temperature, pressure, and relative humidity using standard moist air (saturation) formulae. Less than $5 \%$ of all RS profiles are rejected because of our criteria, mainly because of overly large temperature inter-level gaps in the defined core region.

The radiosonde data from RS92-GDP version 2 (hereafter denoted GRUAN in this study) have been developed within the GCOS Reference Upper Air Network (GRUAN) (Seidel et al., 2009). GRUAN aims to provide reference quality atmospheric observations with a well-defined set of guidelines how to facilitate the required quality and traceability (Immler et al., 2010). At present, the GRUAN network consists of 16 (candidate) stations world-wide, but not all of them deliver a continuous data flow. GRUAN stations delivering data in 2011 are marked with blue squares in Fig. 2. Only two of them, Lindenberg (Germany) and Ny-Ålesund (Spitsbergen) are already certified according to the standards of GRUAN. Lindenberg is also the lead station and provides the most stable data input to GRUAN currently. The lead station is also where GRUAN data are processed and bias-corrected (Immler and Sommer, 2011; Dirksen et al., 2014). GRUAN data are openly available including rich metadata information and error estimates. The vertical resolution is approximately one second (in terms of sampling time of the ascending radiosonde, which corresponds to approximately 5 to $10 \mathrm{~m}$ on average).

\subsection{Collocation and comparison method}

All data are interpolated to a common logarithmic pressure grid before validation, ranging from 1000 to $10 \mathrm{hPa}$ (near surface to about $35 \mathrm{~km}$ ) on 351 levels. This corresponds to an equidistant grid with a level separation of approximately $100 \mathrm{~m}$. We collocated RS and GPSRO profiles by matching the position of the RS launch site to the mean tangent point of GPSRO, and the launch time of RS to the mean event time

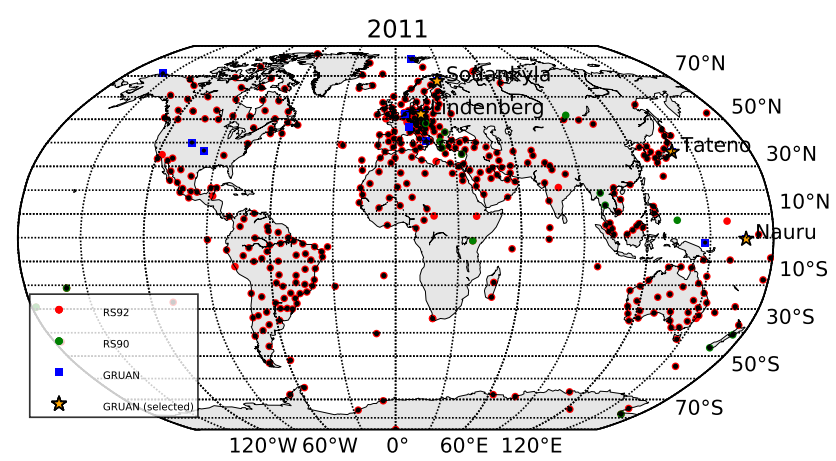

Figure 2. Same layout as Fig. 1, but for 2011. In addition, GRUAN stations with data available in this year are marked in blue. The four GRUAN stations discussed in Sect. 3.4 are marked with an orange star.

of GPSRO. We applied collocation criteria of $300 \mathrm{~km}$ and $3 \mathrm{~h}$. Sun et al. (2010) investigated the influence of imperfect collocation on comparison statistics and found that the criteria merely affect the comparison by increasing the random errors (SD) with larger space/time mismatch. The mean differences are essentially unaffected on the other hand, since the representativity errors from the space/time mismatches are basically random.

For comparison of different data sets it is important to account for diverging effective resolutions. For GPSRO the vertical resolution is dependent on altitude and the specific profile. We performed sensitivity tests smoothing the higherresolved profiles to the lower resolution (Nalli et al., 2013). Since these tests showed only a small decrease in standard deviation we are comparing the interpolated profiles without smoothing to avoid potential biases introduced by the smoothing method.

For averages over pressure layer, we only take into account complete layers; i.e., we do not use layers which include missing values in the respective pressure range. This prevents biases introduced otherwise by those profiles which are systematically cut off at low (GPSRO profiles) or high (RS profiles) altitudes.

\section{Results and discussion}

\subsection{Global seasonal mean differences of GPSRO and RS}

Figure 3 shows the global mean difference between Vaisala RS90/92 data from the ERA-Interim archive (RS) and the WEGC GPSRO data set (GPSRO) for seasonal averages (top), together with SD (middle), and number of collocations (bottom). Temperature differences (left) stay below $0.2 \mathrm{~K}$ for most atmospheric layers. Possible causes for the distinct change in temperature differences from 2005 to 2006 above $200 \mathrm{hPa}$ are analyzed in Sect. 3.3. 

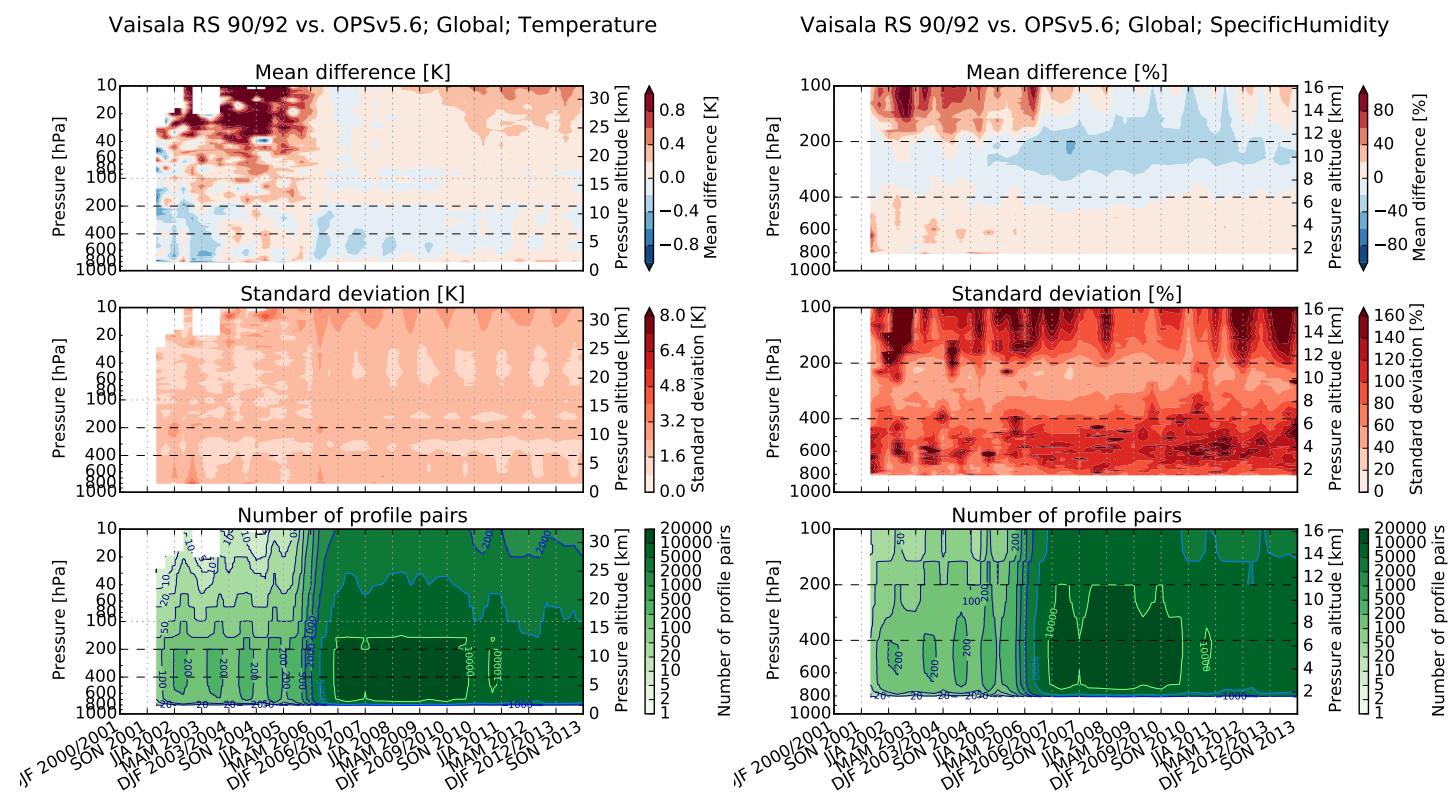

Figure 3. DJF 2001/02 to SON 2013 global-mean seasonal differences for temperature (left) and specific humidity (right) between WEGC GPSRO data and Vaisala RS 90/92 data (top), the related standard deviations (middle), and the associated number of collocations (bottom).

Specific humidity differences (right) stay below $40 \%$ for most layers below $200 \mathrm{hPa}$, but with very large spread. The mean difference shows a slightly positive bias of RS below $400 \mathrm{hPa}$ and a negative bias between 200 and $400 \mathrm{hPa}$ compared to GPSRO. The median (not shown) is negative throughout the whole pressure range, with a very small bias close to $0 \%$ around the lowest available layer from 700 to $800 \mathrm{hPa}$, and reaches $-25 \%$ at $300 \mathrm{hPa}$. Previous studies imply that the negative difference stems from the Vaisala RS92 dry bias (Vömel et al., 2007; J. Wang et al., 2013). Below $400 \mathrm{hPa}$, the WEGC GPSRO optimal estimation retrieval provides humidity profiles with a good measurementto-background information ratio for mid-latitudes (i.e., main information stems from GPSRO measurements there). Here the humidity difference to RS is within $15 \%$. Above $200 \mathrm{hPa}$, due to the very low humidity content, radiosonde humidity information becomes unreliable and GPSRO holds only background information from ECMWF short-range $(24 \mathrm{~h})$ forecast fields. The layer above $200 \mathrm{hPa}$ is only shown for completeness here.

\subsection{Global annual mean differences within pressure layers}

Figures 4 and 5 present core results from a detailed quantitative analysis of systematic temperature differences between RS data and GPSRO data for six representative pressure layers and for the time period 2002 to 2013. To separate and make transparent the potential influence of radiosonde type and GPSRO receiver satellite on the bias, we show differences between the various types separately as well as the differences for the total data set.
Two distinct time periods can be distinguished: 2002 to 2005 with a small number of yearly collocations (generally in the range of 10 to 100) due to sparse data coverage, predominately Vaisala RS90 radiosondes, and only GPSRO CHAMP data available. The temperature differences are relatively large during these first years, especially at high altitudes.

In 2006, the launch of the GPSRO F3C mission, together with a significant rise in the total number of radiosonde launches, led to a strong increase in the number of yearly collocations (up to about 10000). During this time period (2006 to 2013), the launch number of Vaisala RS92 had been increasing significantly while Vaisala RS90 had become less. Starting in 2009, several hundred collocations per year from the GRUAN v2 data set became available and are plotted in addition to the RS data from the ECMWF ERA-Interim archive.

The top pressure layer shown in Fig. 4 (10 to $30 \mathrm{hPa}$ or approximately 25 to $33 \mathrm{~km}$ ) shows the most distinct change in annual mean temperature difference from 2005 to 2006 compared to the lower atmospheric layers. This feature is investigated in detail in Sect. 3.3. The mean temperature difference between RS and GPSRO is 0.5 to $1.0 \mathrm{~K}$ before 2006 and reduces to 0.1 to $0.4 \mathrm{~K}$ after 2006 .

In this altitude region above $25 \mathrm{~km}$, GPSRO becomes increasingly influenced by the background through the highaltitude bending angle initialization (Steiner et al., 2013). A residual ionospheric error might also be of importance at these altitudes (Liu et al., 2013). This error depends on solar activity, which increased from 2009 to 2013 (Danzer et al., 2013). At $30 \mathrm{~km}$ the residual ionospheric error can amount 

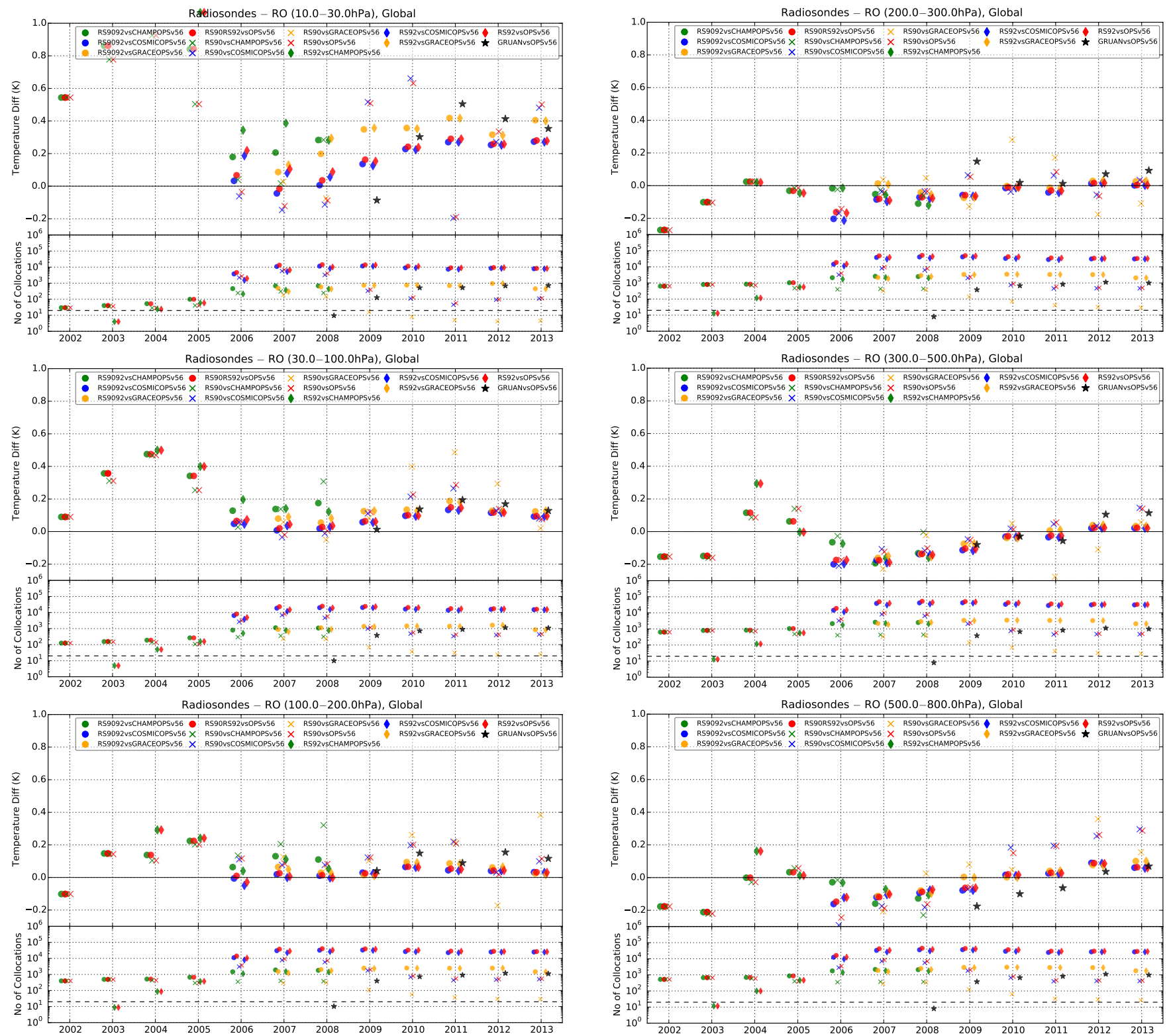

Figure 4. Global annual mean temperature differences over 2002 to 2013 between RS and GPSRO for stratospheric pressure layers 10 to $30 \mathrm{hPa}$ (top), 30 to $100 \mathrm{hPa}$ (middle), and 100 to $200 \mathrm{hPa}$ (bottom). Different RS instrument types and different GPSRO missions (corresponding to different receivers) are indicated by different symbols and colors as summarized in the in-panel legend. RS90RS92 indicates the combined set of RS90 and RS92 instruments. The number of collocations is shown at the bottom of each panel.

to up to $0.3 \mathrm{~K}$ (up to $0.1 \mathrm{~K}$ at $20 \mathrm{~km}$ ) (Schreiner et al., 2011; Steiner et al., 2011). These systematic uncertainty contributions (see also Sect. 2.1) are accounted for in the GPSRO uncertainty bounds in the detailed intercomparisons following in the next sections (Figs. 6 to 11).

Another distinct feature in this layer is the perceived increase in warm bias from 2008 to 2011. A separate discus-

Figure 5. Same layout as Fig. 4 but shown for tropospheric pressure layers 200 to $300 \mathrm{hPa}$ (top), 300 to $500 \mathrm{hPa}$ (middle), and 500 to $800 \mathrm{hPa}$ (bottom), respectively.

sion relating the warm bias to radiation effects is given in Sect. 3.5.

Furthermore, the number of available radiosonde data points is decreasing in this layer depending on the average balloon burst height. For Vaisala RS92, the residual temperature bias (after correction at the ground station) due to radiative effects is about $0.2 \mathrm{~K}$ (Sun et al., 2013), which is likely an important contribution to the mean bias in Fig. 4 (top panel).

The second layer in Fig. 4 (30 to $100 \mathrm{hPa}$ or approximately 17 to $25 \mathrm{~km}$ ) lies well within the lower stratosphere (i.e., with negligible contributions from the troposphere). This is also part of the range of highest measurement quality for GP- 

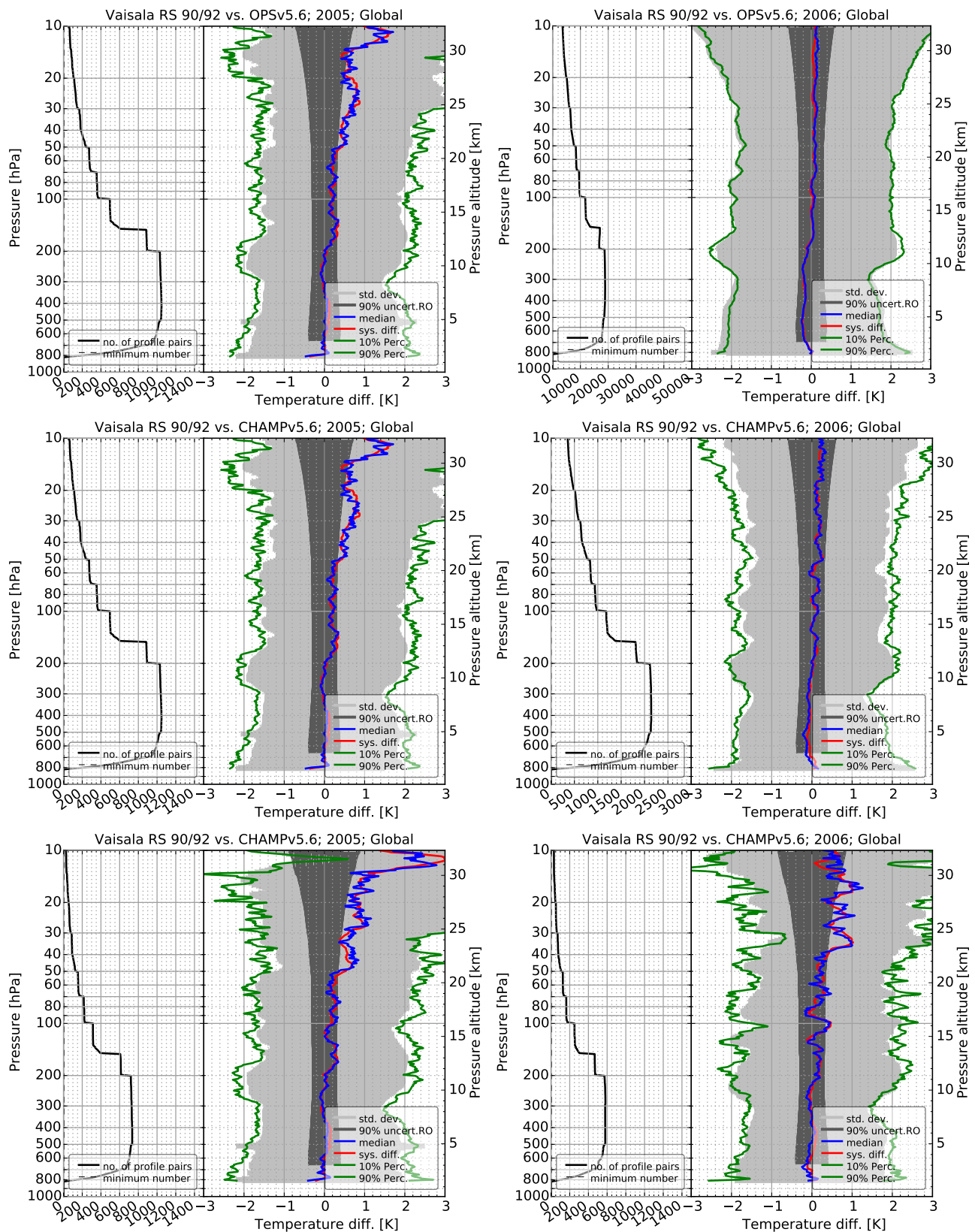

Figure 6. Global mean temperature differences as function of pressure (and pressure altitude, an approximate altitude scale also added for convenience) are shown for the years 2005 (left) and 2006 (right), for Vaisala RS90/92 data versus all GPSRO OPSv5.6 data (top), for Vaisala RS90/92 data versus CHAMP-only GPSRO data (middle), and for Vaisala RS90/92 fixed-station data versus CHAMP-only GPSRO data (bottom), respectively. The number of collocations is shown in the left subpanels.

SRO. The mean differences are smaller than $0.2 \mathrm{~K}$ for most parts in the data-rich time period after 2006. GRUAN mean differences are very similar to the RS data for these global annual means. The larger deviations of GPSRO GRACE and Vaisala RS90 in 2010, 2011, and 2012 can be attributed to the increasingly small sample size of these specific data types (less than 100).

The lowest layer in Fig. 4 and top layer in Fig. 5 (100 to $300 \mathrm{hPa}$ or approximately 9 to $17 \mathrm{~km}$ ) represent upper tropo- spheric, tropopause region, and lower stratospheric pressure levels, depending on latitude and time of the year (Rieckh et al., 2014). These layers are as well part of the range of highest GPSRO data quality. Global mean systematic differences are generally found very small $(<0.1 \mathrm{~K})$, indicating excellent consistency of these different reference records. We consider this a gratifying and very encouraging result for both techniques, given that we must appreciate that radiosondes and GPSRO measure the temperature information by en- 

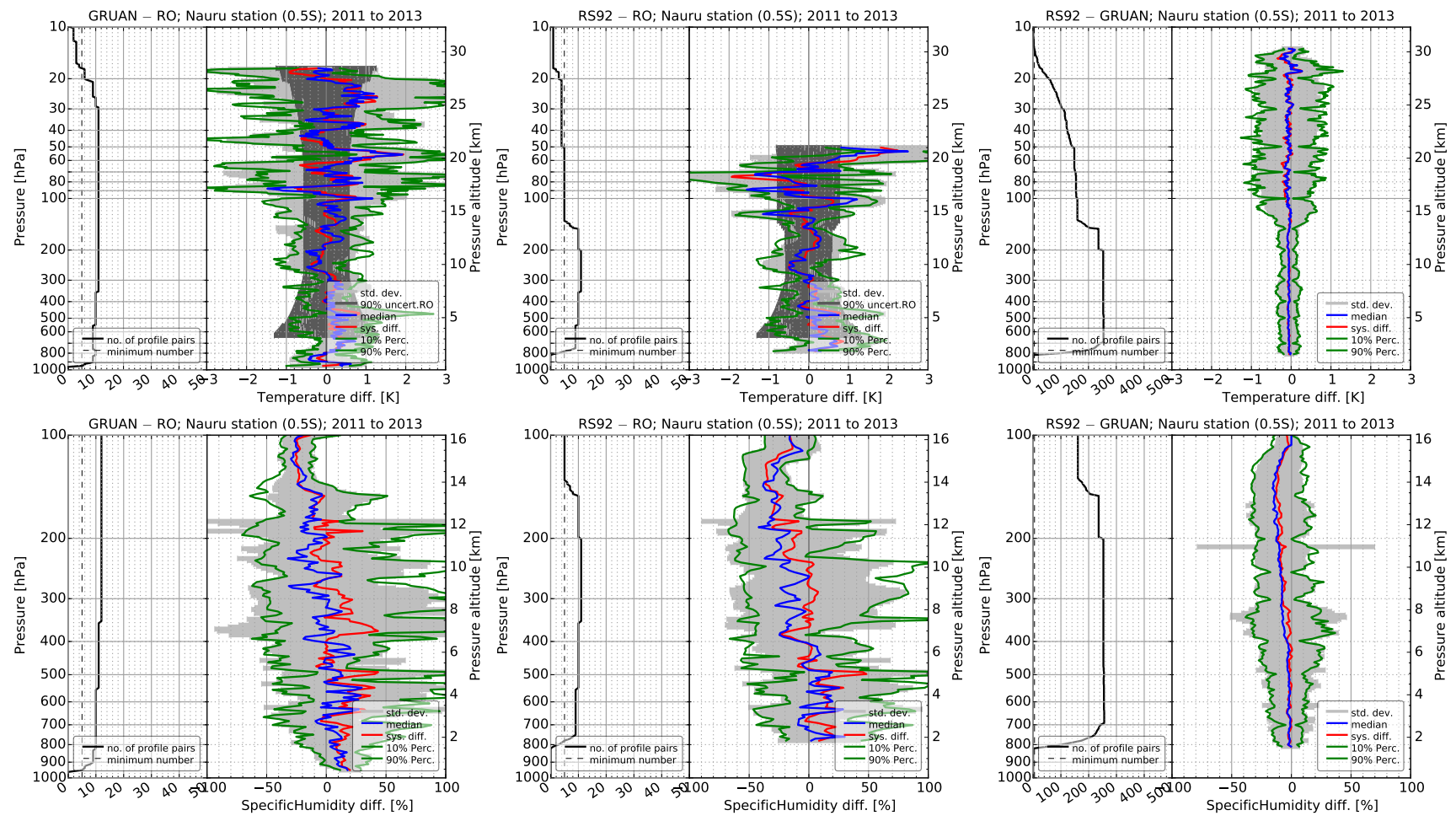

Figure 7. Comparison of temperature (top) and specific humidity (bottom) for the GRUAN station in Nauru, Southwestern Pacific. Differences are shown for GRUAN versus GPSRO (left), RS92 versus GPSRO (middle), and RS92 versus GRUAN (right).

tirely independent measurement principles and very different observational geometries.

The middle and lower tropospheric layers shown in Fig. 5 (300 to $800 \mathrm{hPa}$ or approximately 2 to $9 \mathrm{~km}$ ) contain little temperature information from GPSRO measurements, but are dominated by background temperature information from ECMWF short-range $(24 \mathrm{~h})$ forecasts entering the optimal estimation scheme. This is also discussed in Sect. 3.6. The change in bias from 2006 to 2013 from approximately -0.2 to $0.1 \mathrm{~K}$ might therefore be related to either changes in the ECMWF IFS (Integrated Forecasting System) background data over these years or to changes in the bias correction scheme implemented in the Vaisala RS92 ground stations (Sun et al., 2013).

GRUAN temperature data are found highly consistent with GPSRO and RS data throughout all layers, with somewhat larger differences only in the bottom (300 to $800 \mathrm{hPa})$ and top $(10$ to $30 \mathrm{hPa})$ layers. The deviations in the top layer are discussed in more detail in Sect. 3.5.

\subsection{Change in temperature difference characteristics in 2005/06}

In order to investigate the distinct change in the global mean difference of RS vs. GPSRO between 2005 and 2006 (Figs. 3 and 4), we systematically consider possible causes (illustrated in Fig. 6), focusing our main interest on the top layer (10 to $30 \mathrm{hPa}$ ).
First we investigate the possible influence of transiting from CHAMP-dominated GPSRO data in 2005 to F3Cdominated GPSRO data in 2006 based on the top-row and middle-row panels of Fig. 6. The top-row panels reveal details of the change between 2005 and 2006 when all available GPSRO missions and all RS data are considered. Between 10 and $30 \mathrm{hPa}$, only less than 100 collocations are entering the comparison in 2005 (stemming entirely from CHAMP), while in 2006 this number raises to approximately 4000 with CHAMP and $\mathrm{F} 3 \mathrm{C}$ available. The systematic difference reduces from about $1 \mathrm{~K}$ in 2005 to $0.1 \mathrm{~K}$ in 2006 in this pressure layer. The middle-row panels only consider CHAMP in both years. While the number of CHAMP measurements stays roughly the same for both years, the number of radiosonde launches increases, resulting in a higher number of collocations (approximately 400) in 2006. However, the characteristic differences between 2005 and 2006 do not change significantly against the top-row panels, indicating that introducing an additional GPSRO mission (F3C) to the RO data set is not changing its behavior substantially. This consistency of GPSRO data from different missions has been demonstrated in several studies (Foelsche et al., 2009, 2011; Steiner et al., 2011).

Finally, we investigate the influence of the sample size on the results. In the bottom-row panels of Fig. 6, we limit the radiosonde stations used in the comparison to the ones which have launches in both 2005 and 2006, and collocate 

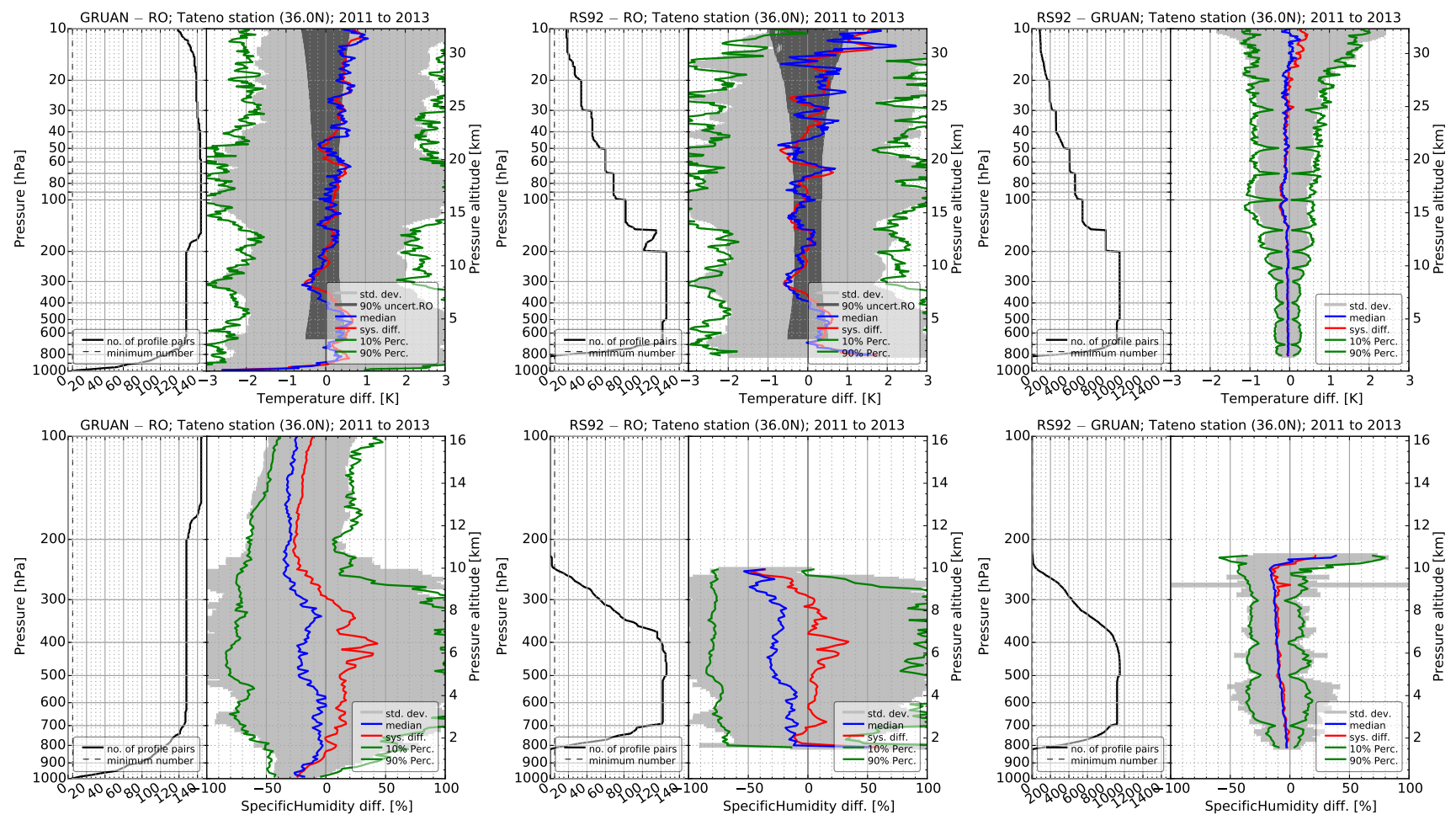

Figure 8. Same layout as Fig. 7, but for the GRUAN station in Tateno, Japan.

only CHAMP GPSRO profiles. The sample size is therefore comparable in this case for 2005 and 2006; it appears that there are less than 50 to 100 profile pairs for both years in the top pressure layer. Other than in the top-row and middlerow panels, the characteristics of the systematic difference become similar between 2005 and 2006 in this case. This indicates that the sample size is the dominating factor of change between the time period 2002 to 2005 and 2006 to 2013.

\subsection{GRUAN stations vs. GPSRO}

In this section, we focus on GRUAN data and present comparisons of four distinct radiosonde stations for the time range 2011 to 2013: Nauru (Southwestern Pacific, $0.5^{\circ} \mathrm{S}$ ), Tateno (Japan, $36.06^{\circ} \mathrm{N}$ ), Lindenberg (Germany, $52.21^{\circ} \mathrm{N}$ ), and Sodankylä (Finland, $67.37^{\circ} \mathrm{N}$ ). These four stations were selected because they represent a diversity of atmospheric conditions from tropical to high latitudes and because they delivered continuous data to the GRUAN archive for almost the whole time range (Tateno delivered continuous data from Vaisala RS92 only from June 2011 to July 2013, when they switched to Meisei RS-11G; the tropical Nauru site closed in August 2013 and has a smaller sample size), and all four stations transmit their data through the GTS. The latter aspect means that they are also available from the ECMWF ERAInterim archive and we can investigate differences between the widely used radiosonde archive at ECMWF and the new reference data set from the GRUAN archive.
For the following, only those RS profiles entered the comparison which also had at least one corresponding profile from the GRUAN archive for each station and launch time. We show differences of temperature and specific humidity between GRUAN and collocated GPSRO, RS and collocated GPSRO, and between GRUAN and RS consecutively for the four stations in Figs. 7-10, respectively.

The four station locations represent regions with different climate regimes, tropics, subtropics, mid-latitudes, and arctic. For all four stations, temperature values are very consistent (within $0.2 \mathrm{~K}$ or less) between GRUAN and RS (top right panels). Remaining differences are partly related to the different vertical sampling delivered in the two data products, and to the small number of remaining sample points at high altitudes. The distinct vertical discontinuities in standard deviation and bias of temperature differences indicate that at the significant levels reported by GTS the difference between GRUAN and RS becomes negligible.

Both comparisons, of GRUAN with GPSRO and of RS with GPSRO, show good agreement at lower altitudes and an increasing positive bias at higher altitudes. Due to the low number of remaining collocations between RS and GPSRO, especially for Nauru, Tateno and Sodankylä stations at high altitudes, the comparisons become very noisy there so that the bias is difficult to attribute; it essentially stays within the estimated GPSRO uncertainty range.

For specific humidity, GRUAN data undergo substantial bias corrections (Dirksen et al., 2014), which is reflected 

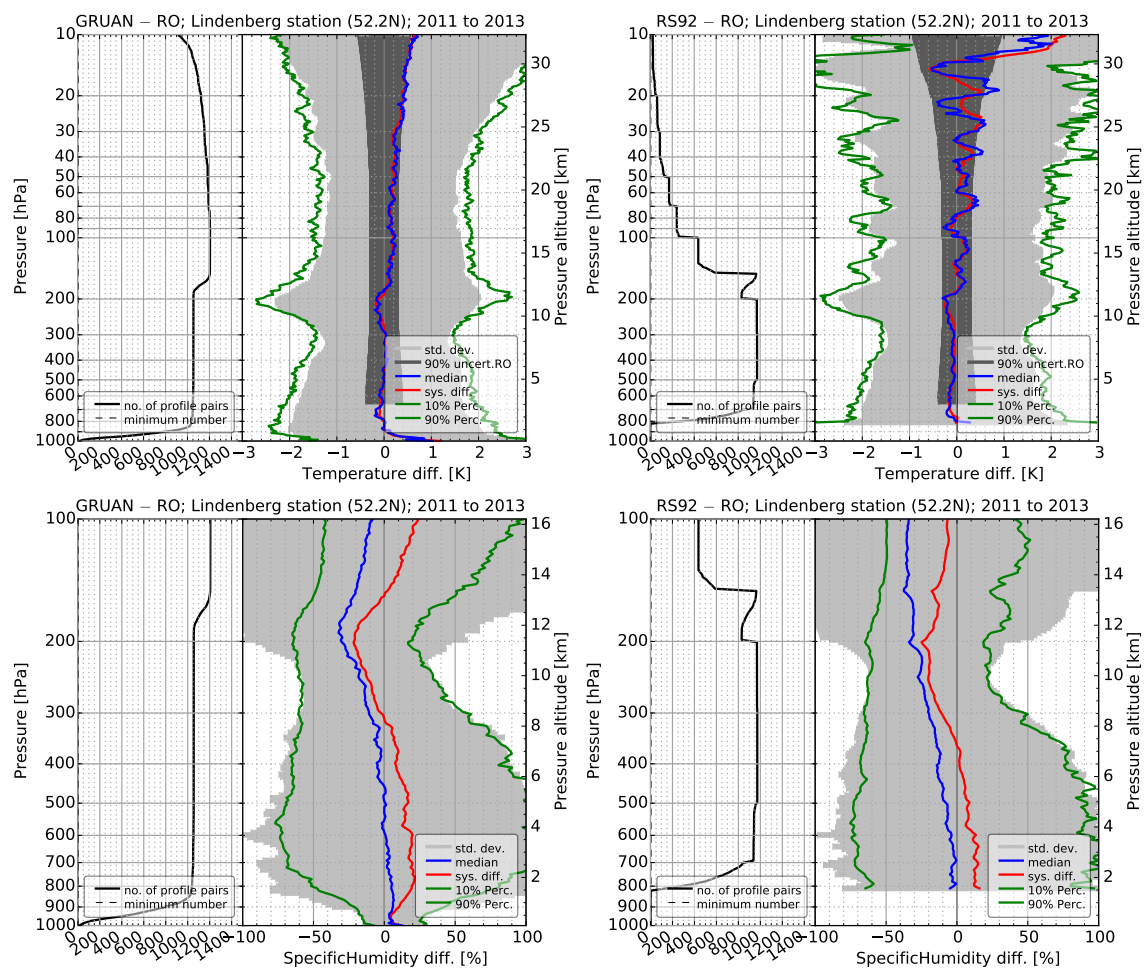
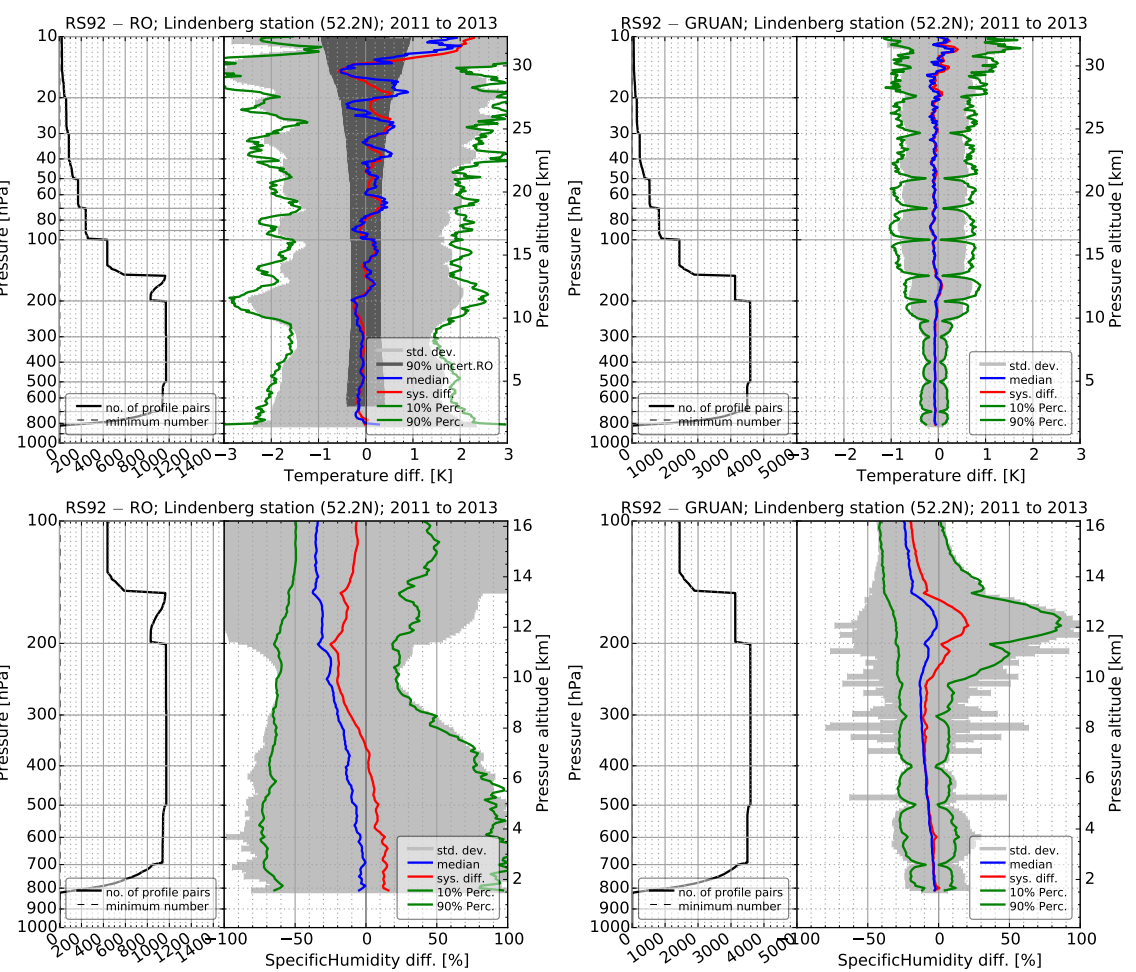

Figure 9. Same layout as Fig. 7, but for the GRUAN station in Lindenberg, Germany.
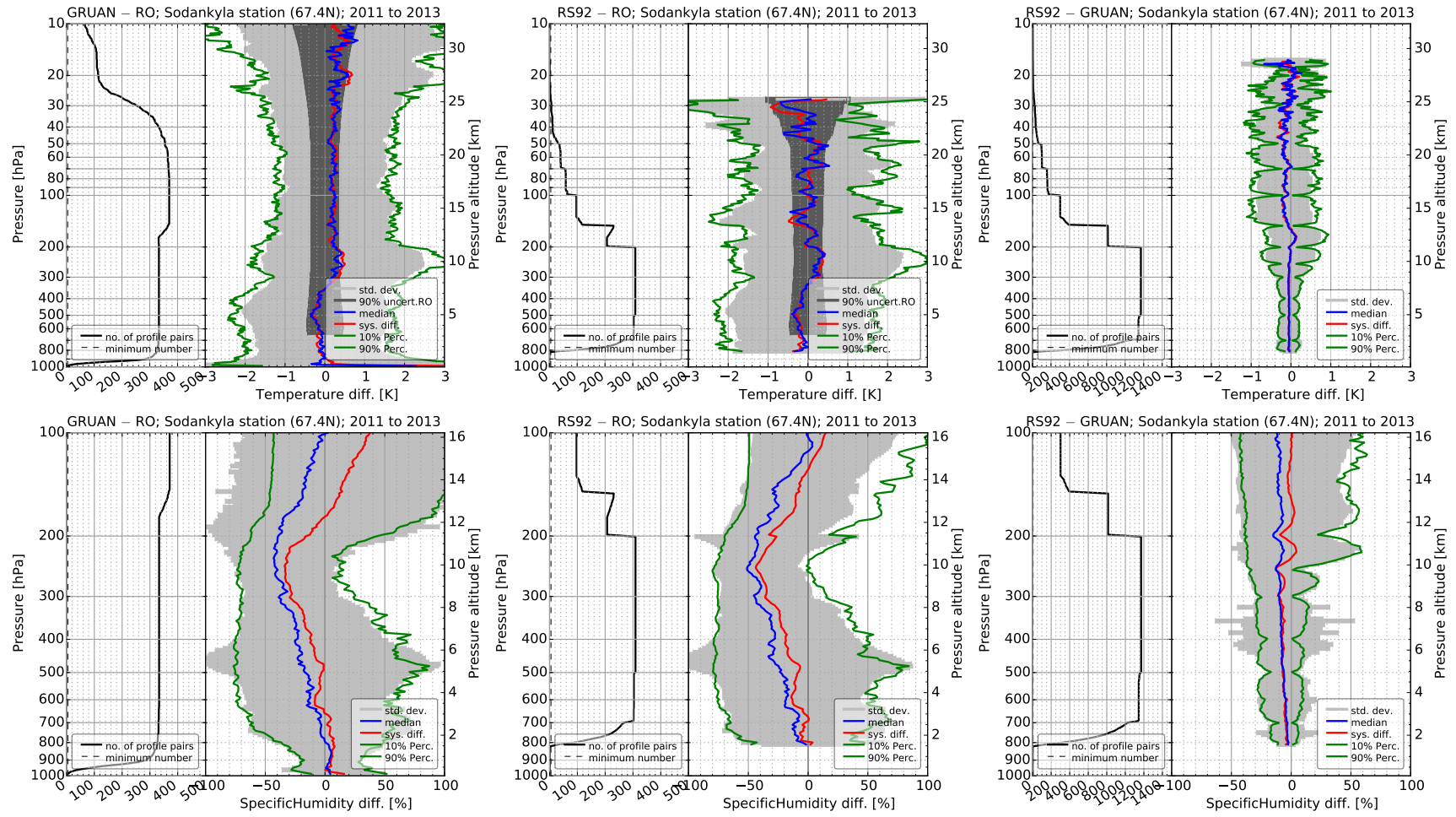

Figure 10. Same layout as Fig. 7, but for the GRUAN station in Sodankylä, Finland. 

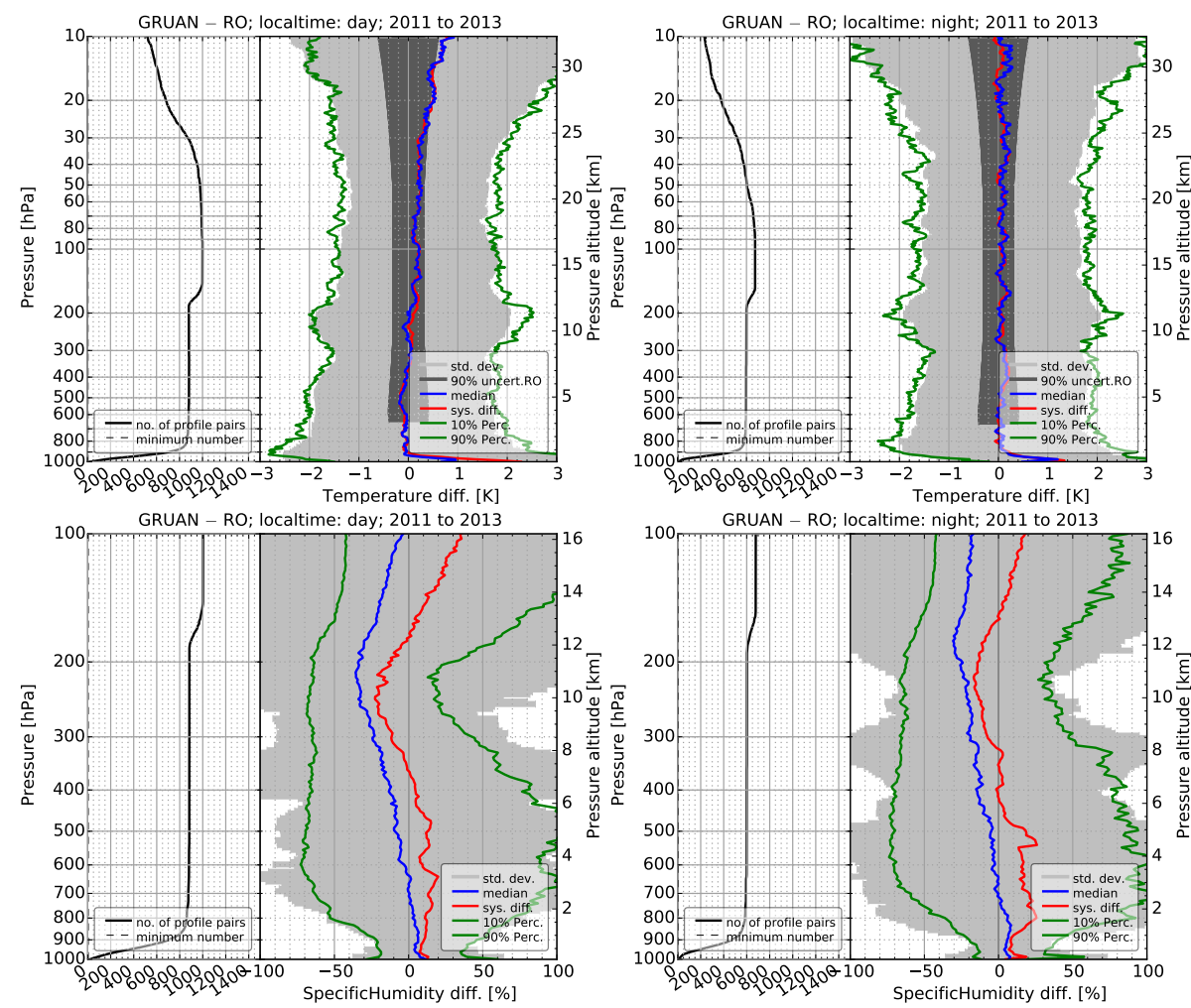

Figure 11. Daytime (left) and nighttime (right) differences as function of pressure/altitude of GRUAN versus GPSRO, for temperature (top) and specific humidity (bottom).

in our results: for the Tateno station, the specific humidity bias reduces by about $10 \%$ in comparison to the difference between RS and GPSRO. The dry bias between 800 and $300 \mathrm{hPa}$ amounts to 5 to $30 \%$. For the Lindenberg station (with a much higher number of about 1000 collocations), the humidity error for GRUAN data in comparison to GPSRO is less than $10 \%$, which again is around $10 \%$ smaller than the difference between RS and GPSRO. A similar improvement can be seen also at the Sodankylä station. A remarkable exception is the tropical station in Nauru, where there is no visible bias between RS and GRUAN below $400 \mathrm{hPa}$, and a dry bias is only emerging above. The difference between RS and GPSRO profiles for Nauru comes from a very small sample size and is only shown for completeness.

In summary, our results underline the quality of the GRUAN data, with a particular improvement in humidity values.

\subsection{GRUAN/RS day and night vs. GPSRO}

Biases in radiosonde temperature data occur mainly due to radiation effects (e.g., Luers and Eskridge, 1998; Sun et al., 2013), typically leading to a warm bias during daytime from incoming solar radiation and to a cold bias during nighttime due to long-wave radiation emitted from the temperature sensor. The humidity measurement is also affected by radiation and results in a dry bias during daytime, most likely caused by solar heating of the sensor, which results in reporting a lower humidity (Vömel et al., 2007).

Radiosonde manufactures usually implement their own correction algorithm for radiation errors, which is applied at the ground station before the data are transmitted. These corrections might change over time and will introduce discontinuities in the data stream (for Vaisala, see the "Sounding Data Continuity" page on www.vaisala.com).

The GRUAN processing implements a radiation correction (described in detail in Dirksen et al., 2014). In this section, we compare day and night soundings with collocated GPSRO profiles to quantify the residual radiation bias. In Fig. 11, we use all available GRUAN RS92-GDP v2 soundings between 2011 and 2013 and its collocated GPSRO profiles and split the validation in daytime (left panels; within 10 a.m. and 2 p.m.) and nighttime (right panels; within 10 p.m. and 2 a.m.). At nighttime, the bias compared to GPSRO stays below $0.2 \mathrm{~K}$ throughout the whole altitude range. At daytime however, a distinct warm bias emerges of up to $0.5 \mathrm{~K}$ at high altitudes. Assuming the likely cause that the daytime radiation effects are not sufficiently corrected, this indicates that above about $25 \mathrm{~km}$, the daytime radiation correction of the GRUAN v2 temperature data leaves in average a warm bias of about $0.3 \mathrm{~K}$. 


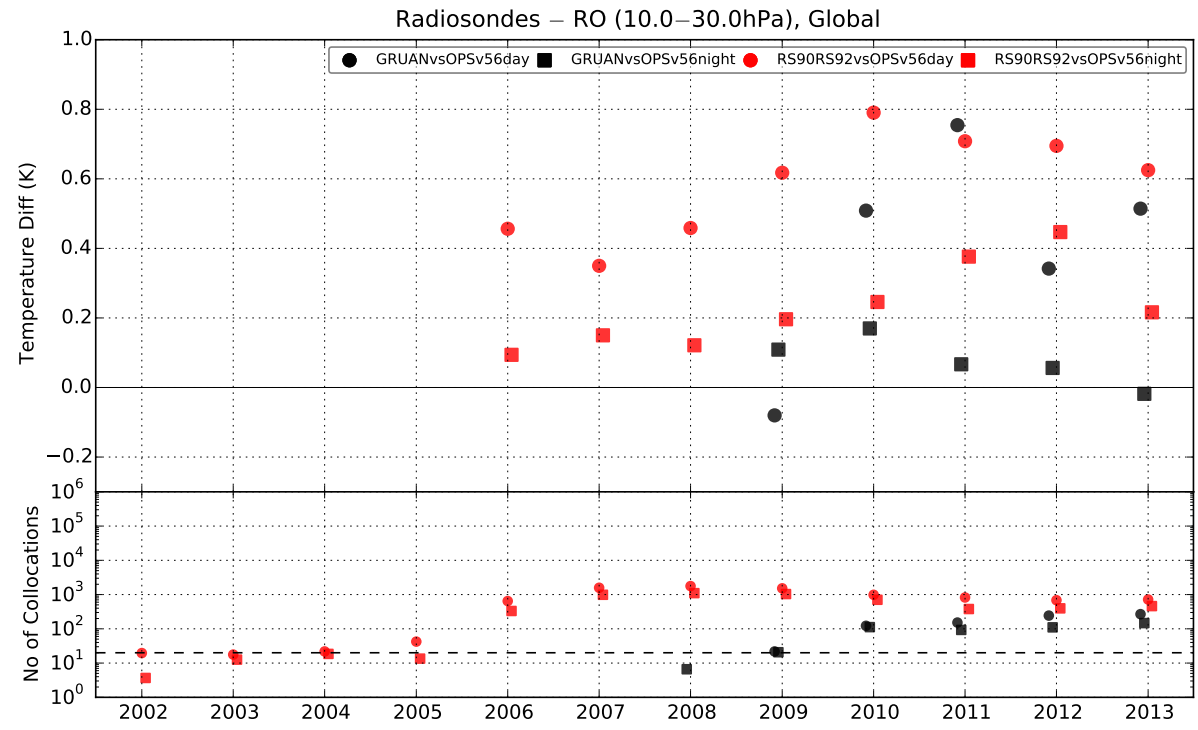

Figure 12. Similar layout as Fig. 4 but showing daytime and nighttime differences for GRUAN versus GPSRO and RS versus GPSRO, for the stratospheric pressure layer 10 to $30 \mathrm{hPa}$.
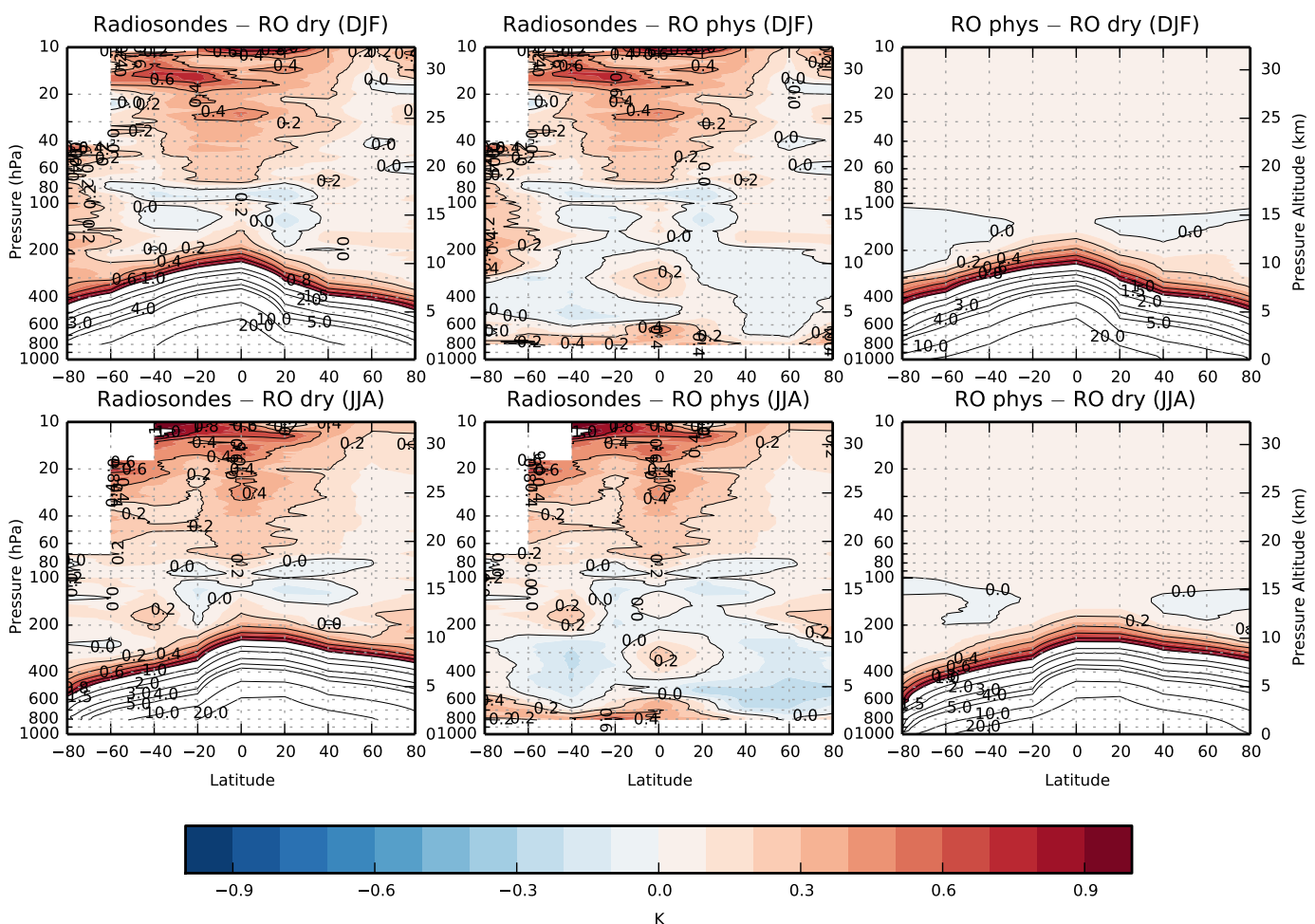

Figure 13. Dry (left) and physical (middle) seasonal mean temperature differences of RS versus GPSRO, and the difference of these two (right), for winter (DJF, top) and for summer (JJA, bottom) for the seven-years mean 2007 to 2013.

Further investigation of the time-dependent radiationinduced bias for both GRUAN and RS is presented in Fig. 12. The increase of warm bias for the 10 to $30 \mathrm{hPa}$ layer from 2008 to 2011 shown in Fig. 4 (top layer) is visible in both day- and nighttime comparisons of RS and GPSRO. The dif- ference in warm bias between day- and nighttime soundings ranges from 0.2 to $0.5 \mathrm{~K}$. The GRUAN temperatures show very good agreement to GPSRO for nighttime (as described above), and a distinct warm bias during daytime. For 
GRUAN data, the warm bias shown in Fig. 4 (top layer) stems therefore mainly from daytime sampling.

The specific humidity bias compared to GPSRO shows, in terms of daytime vs. nighttime difference, only a slightly pronounced dry bias during daytime (Fig. 11 bottom). This indicates that for humidity there occur no appreciable differences between daytime and nighttime GRUAN radiosonde data.

\subsection{GPSRO physical temperature compared to dry temperature}

In this study the GPSRO physical temperature output of the optimal estimation scheme of OPSv5.6 is predominately used. As noted above, the physical temperature will diverge significantly from the GPSRO dry temperature measurement at low altitudes, where the background information dominates in the optimal estimation scheme (Scherllin-Pirscher et al., 2011a; Danzer et al., 2014). Dry temperature, while not a physical parameter, does not need background information in the GPSRO retrieval process and is a valid measure for physical temperature as long as moisture is negligible. In regions in the atmosphere where this condition is met, dry temperature will be equivalent to physical temperature. In this section, we use the comparison to observational (RS) temperature data to determine where we can safely assume them to be equivalent. For a thorough investigation of this question using model data as reference see Danzer et al. (2014). An initial illustration based on monthly climatological fields was included in Scherllin-Pirscher et al. (2011a).

In Fig. 13 we present seasonal means for the time period 2007 to 2013 and two seasons, DJF (northern winter) and JJA (northern summer). Dry temperature (left) is, up to residual noise, always lower than physical temperature, which is well visible. In the tropics, where the moisture content is highest, dry temperature differences to radiosonde temperatures reach $0.4 \mathrm{~K}$ at $200 \mathrm{hPa}$ (approximately $11 \mathrm{~km}$ ) and then further increase downwards. Essentially above the $100 \mathrm{hPa}$ pressure layer, at around $15 \mathrm{~km}$, the difference between dry and physical temperature becomes negligible, i.e., buried within noise. Between 100 and $200 \mathrm{hPa}$, differences are relevant only at tropical latitudes and amount to less than 0.1 to $0.3 \mathrm{~K}$. In the extratropics, the dry temperature stays very close to the physical one down to well below $300 \mathrm{hPa}$.

The intercomparison of the physical temperature (middle) shows that the optimal estimation works well also deep into the troposphere; the GPSRO temperature generally stays close to the RS temperature, within about 0.2 to $0.5 \mathrm{~K}$, down towards the boundary layer near $800 \mathrm{hPa}$. This reflects the quality of the ECMWF short-range temperature forecasts in the troposphere, which dominate the GPSRO physical temperature in the altitude regions where dry temperature significantly deviates from physical temperature.

The difference between physical and dry GPSRO temperature (right) summarizes the results above. In the WEGC GP-
SRO retrieval, the retrieved physical temperature is essentially equal to the dry temperature above $100 \mathrm{hPa}$ (deviating less than $0.01 \mathrm{~K}$; see Sect. 2.1).

\section{Conclusions}

In this paper, we use 12 years of GPSRO measurements, collocated radiosonde soundings from Vaisala RS90/92 sensors, and 5 years of the RS92 GRUAN data product (RS92-GDP) version 2 , to rigorously intercompare temperature and humidity data for these three upper-air observational data sets. While the Vaisala RS90/92 data set from the ECMWF ERAInterim archive is part of the traditional, widely used global radiosonde network with its known deficiencies for longterm climate applications, both GPSRO and GRUAN claim to be of reference quality and suitable for climate research.

We find generally very good agreement between all three data sets, with global annual mean temperature differences of less than $0.2 \mathrm{~K}$ in most analyzed altitude regions over the troposphere and lower stratosphere. In the top layer of our study domain (10 to $30 \mathrm{hPa}$ ), temperature differences are larger (up to $0.5 \mathrm{~K}$ ). Day/night comparison of GRUAN data with GPSRO indicates that this difference is partly related to the wellknown radiosonde radiation bias at high altitudes. This in turn indicates that there is still work to be done to enable reliable stratospheric climate studies with radiosondes.

Potential GPSRO residual errors at these altitudes have also to be taken into account. These errors result mainly from the downward-propagating influence of background information from the high-altitude initialization. Efforts on processing improvements to minimize these errors are ongoing and will further narrow the GPSRO uncertainty estimates in the 25 to $35 \mathrm{~km}$ layer.

For temperature validation studies with GPSRO one has to be aware of the difference between the GPSRO-specific dry temperature parameter (directly useful as temperature in dry-air with negligible moisture) and physical temperature. The latter includes background information (from ECMWF short-range forecast fields) in the lower and middle troposphere. In the tropics at $200 \mathrm{hPa}$, the difference of GPSRO dry temperature to RS is about $0.4 \mathrm{~K}$, further decreasing upwards and decreasing towards the extratropics where differences remain less than $0.2 \mathrm{~K}$ to well below $300 \mathrm{hPa}$.

For specific humidity, Vaisala RS90/92 data show a dry bias of up to $40 \%$ in the troposphere, with a smaller bias at lower altitudes within $15 \%$ and generally a very large SD. The median is negative throughout the whole altitude range; it starts at close to $0 \%$ in the lower troposphere and reaches about $-25 \%$ at $300 \mathrm{hPa}$.

GRUAN, with its substantial humidity bias correction scheme, shows a marked improvement in the dry bias compared to the "raw" Vaisala RS92 data, taking GPSRO as reference. At the GRUAN lead station Lindenberg, specific humidity agrees within $5 \%$ with GPSRO up to $300 \mathrm{hPa}$. At the tropical GRUAN station (Nauru), the Vaisala RS92 humidity 
data is in good agreement with GRUAN, indicating that the dry bias might be smaller in the tropical regime.

Using three GPSRO missions with a significantly different number of profiles also helped to analyze the influence of the number of collocations (sample size) on validation results, which was found to be the major reason for the qualitative improvement in the degree of agreement between the data sets as of 2006. Before 2006, in the CHAMP-only time period, it is difficult to get a sufficient number of collocations with radiosonde launches, and comparison results become statistically robust only after the launch of the COSMIC mission.

This points to the urgent need of a continuation of GPSRO missions with a sufficient number of GPSRO observations, at least 20000 events per day is considered a required number for climate and other applications, including at regional scales. Likewise the current sampling by GRUAN stations is very sparse and a swift extension of the GRUAN network to its intended size of several dozen stations worldwide is highly desirable.

Climate applications using data from the global radiosonde network face difficulties how to interpret the data due to the large number of different radiosonde types, the varying error characteristics, insufficient global coverage, and instrument biases. Reference data to anchor these measurements are therefore of great importance. The GRUAN effort is a vital contribution to this goal, with their data adhering to the climate monitoring principles stated by GCOS. GPSRO adds to that global coverage and stratospheric extend and, as an observing system independent from radiosondes, serves as another fundamentally needed source of thermodynamic reference in the free atmosphere.

Overall very good agreement is demonstrated by this multi-year intercomparison of GPSRO and radiosonde reference data sets. This strongly encourages further development and advancement of both systems for the benefit of future climate monitoring and research.

Acknowledgements. We thank UCAR/CDAAC (Boulder, CO, USA) for RO phase and orbit data, GRUAN (Deutscher Wetterdienst - DWD, Germany) for access to GRUAN data, and ECMWF (Reading, UK) for access to forecast data and the ERA-Interim observation archive. We are grateful to L. Haimberger (University of Vienna, Austria) for valuable assistance in retrieving radiosonde data from the ERA-Interim archive. We acknowledge the WEGC RO processing team, especially J. Fritzer, for contribution to RO processing system development and operations. Furthermore, we are very thankful to B. Scherllin-Pirscher (WEGC) for fruitful discussions. The work was funded by the Austrian Science Fund (FWF) grants P21642N21 and T620-N29, by the ESA/ESRIN project MMValRO-E (ESA contract no. 4000110769/14/I-AM), and regarding OPS development also by the ESA/ESTEC project OPSGRAS and the Austrian Research Promotion Agency (FFG) projects OPSCLIMPROP/OPSCLIMTRACE.

Edited by: R. Anthes

\section{References}

Anthes, R. A.: Exploring Earth's atmosphere with radio occultation: contributions to weather, climate and space weather, Atmos. Meas. Tech., 4, 1077-1103, doi:10.5194/amt-4-1077-2011, 2011.

Anthes, R. A., Bernhardt, P. A., Chen, Y., Cucurull, L., Dymond, K. F., Ector, D., Healy, S. B., Ho, S.-P., Hunt, D. C., Kuo, Y.H., Liu, H., Manning, K., McCormick, C., Meehan, T. K., Randel, W. J., Rocken, C., Schreiner, W. S., Sokolovskiy, S. V., Syndergaard, S., Thompson, D. C., Trenberth, K. E., Wee, T.K., Yen, N. L., and Zeng, Z.: The COSMIC/FORMOSAT-3 mission: Early results, B. Am. Meteorol. Soc., 89, 313-333, doi:10.1175/BAMS-89-3-313, 2008.

Beyerle, G., Schmidt, T., Michalak, G., Heise, S., Wickert, J., and Reigber, C.: GPS radio occultation with GRACE: Atmospheric profiling utilizing the zero difference technique, Geophys. Res. Lett., 32, L13806, doi:10.1029/2005GL023109, 2005.

Danzer, J., Scherllin-Pirscher, B., and Foelsche, U.: Systematic residual ionospheric errors in radio occultation data and a potential way to minimize them, Atmos. Meas. Tech., 6, 2169-2179, doi:10.5194/amt-6-2169-2013, 2013.

Danzer, J., Foelsche, U., Scherllin-Pirscher, B., and Schwärz, M.: Influence of changes in humidity on dry temperature in GPS RO climatologies, Atmos. Meas. Tech., 7, 2883-2896, doi:10.5194/amt-7-2883-2014, 2014.

Dirksen, R. J., Sommer, M., Immler, F. J., Hurst, D. F., Kivi, R., and Vömel, H.: Reference quality upper-air measurements: GRUAN data processing for the Vaisala RS92 radiosonde, Atmos. Meas. Tech., 7, 4463-4490, doi:10.5194/amt-7-4463-2014, 2014.

Foelsche, U., Pirscher, B., Borsche, M., Kirchengast, G., and Wickert, J.: Assessing the climate monitoring utility of radio occultation data: From CHAMP to FORMOSAT3/COSMIC, Terr. Atmos. Ocean. Sci., 20, 155-170, doi:10.3319/TAO.2008.01.14.01(F3C), 2009.

Foelsche, U., Scherllin-Pirscher, B., Ladstädter, F., Steiner, A. K., and Kirchengast, G.: Refractivity and temperature climate records from multiple radio occultation satellites consistent within $0.05 \%$, Atmos. Meas. Tech., 4, 2007-2018, doi:10.5194/amt-4-2007-2011, 2011.

GCOS: Implementation plan for the global observing system for climate in support of the UNFCCC (2010 update), WMOTD/No. 1523, WMO, Geneva, GCOS-138, 2010.

GCOS: Systematic Observation Requirements for Satellite-based Products for Climate (2011 Update), GCOS-154, WMO, Geneva, 2011.

Gorbunov, M. E., Benzon, H.-H., Jensen, A. S., Lohmann, M. S., and Nielsen, A. S.: Comparative analysis of radio occultation processing approaches based on Fourier integral operators, Radio Sci., 39, RS6004, doi:10.1029/2003RS002916, 2004.

Haimberger, L., Tavolato, C., and Sperka, S.: Toward elimination of the warm bias in historic radiosonde temperature records - some new results from a comprehensive intercomparison of upper-air data, J. Climate, 21, 4587-4606, doi:10.1175/2008JCLI1929.1, 2008.

Haimberger, L., Tavolato, C., and Sperka, S.: Homogenization of the Global Radiosonde Temperature Dataset through Combined Comparison with Reanalysis Background Series and Neighboring Stations, J. Climate, 25, 8108-8131, doi:10.1175/JCLI-D-11$00668.1,2012$. 
He, W., Ho, S.-P., Chen, H., Zhou, X., Hunt, D., and Kuo, Y.-H.: Assessment of radiosonde temperature measurements in the upper troposphere and lower stratosphere using COSMIC radio occultation data, Geophys. Res. Lett., 36, L17807, doi:10.1029/2009GL038712, 2009.

Ho, S.-P., Kuo, Y.-H., Zeng, Z., and Peterson, T.: A comparison of lower stratospheric temperature from microwave measurements with CHAMP GPS RO data, Geophys. Res. Lett., 34, L15701, doi:10.1029/2007GL030202, 2007.

Ho, S.-P., Zhou, X., Kuo, Y.-H., Hunt, D., and Wang, J.-H.: Global evaluation of radiosonde water vapor systematic biases using GPS radio occultation from COSMIC and ECMWF analysis, Remote Sensing, 2, 1320-1330, doi:10.3390/RS2051320, 2010.

Ho, S.-P., Hunt, D., Steiner, A. K., Mannucci, A. J., Kirchengast, G., Gleisner, H., Heise, S., von Engeln, A., Marquardt, C., Sokolovskiy, S., Schreiner, W., Scherllin-Pirscher, B., Ao, C., Wickert, J., Syndergaard, S., Lauritsen, K., Leroy, S., Kursinski, E. R., Kuo, Y.-H., Foelsche, U., Schmidt, T., and Gorbunov, M.: Reproducibility of GPS radio occultation data for climate monitoring: Profile-to-profile inter-comparison of CHAMP climate records 2002 to 2008 from six data centers, J. Geophys. Res., 117, D18111, doi:10.1029/2012JD017665, 2012.

Immler, F. and Sommer, M.: Brief Description of the RS92 GRUAN Data Product (RS92-GDP), Gruan technical document 4 (gruantd-4), GRUAN Lead Centre, 2011.

Immler, F. J., Dykema, J., Gardiner, T., Whiteman, D. N., Thorne, P. W., and Vömel, H.: Reference Quality Upper-Air Measurements: guidance for developing GRUAN data products, Atmos. Meas. Tech., 3, 1217-1231, doi:10.5194/amt-3-1217-2010, 2010.

IPCC: Climate Change 2013: The Physical Science Basis. Contribution of Working Group I to the Fifth Assessment Report of the Intergovernmental Panel on Climate Change, Cambridge University Press, Cambridge, UK and New York, NY, USA, 2013.

Karl, T. R., Hassol, S. J., Miller, C. D., and Murray, W. L.: Temperature Trends in the Lower Atmosphere: Steps for Understanding and Reconciling Differences, Report, Climate Change Science Program and the Subcommittee on Global Change Research, Washington, DC, USA, 2006.

Kuo, Y.-H., Schreiner, W. S., Wang, J., Rossiter, D. L., and Zhang, Y.: Comparison of GPS radio occultation soundings with radiosondes, Geophys. Res. Lett., 32, L05817, doi:10.1029/2004GL021443, 2005.

Kursinski, E. R., Hajj, G. A., Schofield, J. T., Linfield, R. P., and Hardy, K. R.: Observing Earth's atmosphere with radio occultation measurements using the Global Positioning System, J. Geophys. Res., 102, 23429-23465, doi:10.1029/97JD01569, 1997.

Ladstädter, F., Steiner, A. K., Foelsche, U., Haimberger, L., Tavolato, C., and Kirchengast, G.: An assessment of differences in lower stratospheric temperature records from (A)MSU, radiosondes, and GPS radio occultation, Atmos. Meas. Tech., 4, 1965-1977, doi:10.5194/amt-4-1965-2011, 2011.

Leroy, S. S., Dykema, J. A., and Anderson, J. G.: Climate benchmarking using GNSS occultation, in: Atmosphere and Climate: Studies by Occultation Methods, edited by: Foelsche, U., Kirchengast, G., and Steiner, A. K., 287-302, Springer, BerlinHeidelberg, Germany, 2006.

Liu, C.-L., Kirchengast, G., Zhang, K., Norman, R., Li, Y., Zhang, S. C., Carter, B., Fritzer, J., Schwaerz, M., Choy, S. L., Wu, S. Q., and Tan, Z. X.: Characterisation of residual ionospheric errors in bending angles using GNSS RO end-to-end simulations, Adv. Space Res., 52, 821-836, doi:10.1016/j.asr.2013.05.021, 2013.

Luers, J. K. and Eskridge, R. E.: Use of Radiosonde Temperature Data in Climate Studies, J. Climate, 11, 1002-1019, doi:10.1175/1520-0442(1998)011<1002:UORTDI>2.0.CO;2, 1998.

Mears, C. A. and Wentz, F. J.: Construction of the Remote Sensing Systems V3.2 Atmospheric Temperature Records from the MSU and AMSU Microwave Sounders, J. Atmos. Ocean. Tech., 26, 1040-1056, doi:10.1175/2008JTECHA1176.1, 2008.

Melbourne, W. G., Davis, E. S., Duncan, C. B., Hajj, G. A., Hardy, K. R., Kursinski, E. R., Meehan, T. K., Young, L. E., and Yunck, T. P.: The application of spaceborne GPS to atmospheric limb sounding and global change monitoring, JPL Publication, 94-18, 147, 1994.

Miloshevich, L. M., Vömel, H., Whiteman, D. N., Lesht, B. M., Schmidlin, F. J., and Russo, F.: Absolute accuracy of water vapor measurements from six operational radiosonde types launched during AWEX-G and implications for AIRS validation, J. Geophys. Res., 111, D09S10, doi:10.1029/2005JD006083, 2006.

Nalli, N. R., Barnet, C. D., Reale, A., Tobin, D., Gambacorta, A., Maddy, E. S., Joseph, E., Sun, B., Borg, L., Mollner, A. K., Morris, V. R., Liu, X., Divakarla, M., Minnett, P. J., Knuteson, R. O., King, T. S., and Wolf, W. W.: Validation of satellite sounder environmental data records: Application to the Cross-track Infrared Microwave Sounder Suite, J. Geophys. Res., 118, 13628-13643, doi:10.1002/2013JD020436, 2013.

Nash, J., Oakley, T., Vömel, H., and Wei, L.: WMO Intercomparison of High Quality Radiosonde Systems, WMO/TD-No. 1580, World Meteorological Organization (WMO), 2011.

Randel, W. J., Shine, K. P., Austin, J., Barnett, J., Claud, C., Gillett, N. P., Keckhut, P., Langematz, U., Lin, R., Long, C., Mears, C., Miller, A., Nash, J., Seidel, D. J., Thompson, D. W. J., Wu, F., and Yoden, S.: An update of observed stratospheric temperature trends, J. Geophys. Res., 114, D02107, doi:10.1029/2008JD010421, 2009.

Rieckh, T., Scherllin-Pirscher, B., Ladstädter, F., and Foelsche, U.: Characteristics of tropopause parameters as observed with GPS radio occultation, Atmos. Meas. Tech., 7, 3947-3958, doi:10.5194/amt-7-3947-2014, 2014.

Santer, B. D., Thorne, P. W., Haimberger, L., Taylor, K. E., Wigley, T. M. L., Lanzante, J. R., Solomon, S., Free, M., Gleckler, P. J., Jones, P. D., Karl, T. R., Klein, S. A., Mears, C., Nychka, D., Schmidt, G. A., Sherwood, S. C., and Wentz, F. J.: Consistency of modelled and observed temperature trends in the tropical troposphere, Int. J. Climatol., 28, 1703-1722, doi:10.1002/joc.1756, 2008.

Scherllin-Pirscher, B., Kirchengast, G., Steiner, A. K., Kuo, Y.H., and Foelsche, U.: Quantifying uncertainty in climatological fields from GPS radio occultation: an empirical-analytical error model, Atmos. Meas. Tech., 4, 2019-2034, doi:10.5194/amt-42019-2011, 2011a.

Scherllin-Pirscher, B., Steiner, A. K., Kirchengast, G., Kuo, Y.-H., and Foelsche, U.: Empirical analysis and modeling of errors of atmospheric profiles from GPS radio occultation, Atmos. Meas. Tech., 4, 1875-1890, doi:10.5194/amt-4-1875-2011, 2011 b.

Schreiner, W., Kuo, Y.-H., Ho, S.-P., Sokolovskiy, S., and Hunt, D.: Use of GNSS Radio Occultation data for Climate Applications, World Climate Research Program Conference, 24-28 October 
2011, Denver, CO, USA, http://www.cosmic.ucar.edu/groupAct/ references/WCRP-2011-Schreiner-Final.pdf (last access: April 2015), 2011.

Schwärz, M., Scherllin-Pirscher, B., Kirchengast, G., Schwarz, J., Ladstädter, F., Fritzer, J., and Ramsauer, J.: Multi-Mission Validation by Satellite Radio Occultation, Final report for ESA/ESRIN No. 01/2013, WEGC, University of Graz, Austria, 2013.

Seidel, D. J., Berger, F. H., Immler, F., Sommer, M., Vömel, H., Diamond, H. J., Dykema, J., Goodrich, D., Murray, W., Peterson, T., Sisterson, D., Thorne, P., and Wang, J.: Reference Upper-Air Observations for Climate: Rationale, Progress, and Plans, B. Am. Meteorol. Soc., 90, 361-369, doi:10.1175/2008BAMS2540.1, 2009.

Smith, E. and Weintraub, S.: The constants in the equation for atmospheric refractive index at radio frequencies, Proc. IRE, 41, 1035-1037, 1953.

Steiner, A. K., Kirchengast, G., Borsche, M., Foelsche, U., and Schoengassner, T.: A multi-year comparison of lower stratospheric temperatures from CHAMP radio occultation data with MSU/AMSU records, J. Geophys. Res., 112, D22110, doi:10.1029/2006JD008283, 2007.

Steiner, A. K., Lackner, B. C., Ladstädter, F., Scherllin-Pirscher, B., Foelsche, U., and Kirchengast, G.: GPS radio occultation for climate monitoring and change detection, Radio Sci., 46, RSOD24, doi:10.1029/2010RS004614, 2011.

Steiner, A. K., Hunt, D., Ho, S.-P., Kirchengast, G., Mannucci, A. J., Scherllin-Pirscher, B., Gleisner, H., von Engeln, A., Schmidt, T., Ao, C., Leroy, S. S., Kursinski, E. R., Foelsche, U., Gorbunov, M., Heise, S., Kuo, Y.-H., Lauritsen, K. B., Marquardt, C., Rocken, C., Schreiner, W., Sokolovskiy, S., Syndergaard, S., and Wickert, J.: Quantification of structural uncertainty in climate data records from GPS radio occultation, Atmos. Chem. Phys., 13, 1469-1484, doi:10.5194/acp-13-1469-2013, 2013.

Sun, B., Reale, A., Seidel, D. J., and Hunt, D. C.: Comparing radiosonde and COSMIC atmospheric profile data to quantify differences among radiosonde types and the effects of imperfect collocation on comparison statistics, J. Geophys. Res., 115, D23104, doi:10.1029/2010JD014457, 2010.

Sun, B., Reale, A., Schroeder, S., Seidel, D. J., and Ballish, B.: Toward improved corrections for radiation-induced biases in radiosonde temperature observations, J. Geophys. Res., 118, 42314243, doi:10.1002/jgrd.50369, 2013.
Thorne, P., Parker, D., Christy, J., and Mears, C.: Uncertainties in climate trends: Lessons from upper-air temperature records, B. Am. Meteorol. Soc., 86, 1437-1442, doi:10.1175/BAMS-86-101437, 2005.

Thorne, P. W., Brohan, P., Titchner, H. A., McCarthy, M. P., Sherwood, S. C., Peterson, T. C., Haimberger, L., Parker, D. E., Tett, S. F. B., Santer, B. D., Fereday, D. R., and Kennedy, J. J.: A quantification of uncertainties in historical tropical tropospheric temperature trends from radiosondes, J. Geophys. Res., 116, D12116, doi:10.1029/2010JD015487, 2011a.

Thorne, P. W., Lanzante, J. R., Peterson, T. C., Seidel, D. J., and Shine, K. P.: Tropospheric temperature trends: history of an ongoing controversy, WIREs Clim. Change, 2, 66-88, doi:10.1002/wcc.80, 2011b.

Titchner, H. A., Thorne, P. W., McCarthy, M. P., Tett, S. F., Haimberger, L., and Parker, D. E.: Critically reassessing tropospheric temperature trends from radiosondes using realistic validation experiments, J. Climate, 22, 465-485, doi:10.1175/2008JCLI2419.1, 2009.

Vömel, H., Selkirk, H., Miloshevich, L., Valverde-Canossa, J., Valdés, J., Kyrö, E., Kivi, R., Stolz, W., Peng, G., and Diaz, J. A.: Radiation Dry Bias of the Vaisala RS92 Humidity Sensor, J. Atmos. Ocean. Tech., 24, 953-963, doi:10.1175/JTECH2019.1, 2007.

Wang, B.-R., Liu, X.-Y., and Wang, J.-K.: Assessment of COSMIC radio occultation retrieval product using global radiosonde data, Atmos. Meas. Tech., 6, 1073-1083, doi:10.5194/amt-6-10732013, 2013.

Wang, J., Zhang, L., Dai, A., Immler, F., Sommer, M., and Vömel, H.: Radiation Dry Bias Correction of Vaisala RS92 Humidity Data and Its Impacts on Historical Radiosonde Data, J. Atmos. Ocean. Tech., 30, 197-214, doi:10.1175/JTECH-D-12-00113.1, 2013.

Wang, W. and Zou, C.-Z.: AMSU-A-Only Atmospheric Temperature Data Records from the Lower Troposphere to the Top of the Stratosphere, J. Atmos. Ocean. Tech., 31, 808-825, doi:10.1175/JTECH-D-13-00134.1, 2014.

Wickert, J., Reigber, C., Beyerle, G., König, R., Marquardt, C., Schmidt, T., Grunwaldt, L., Galas, R., Meehan, T., Melbourne, W., and Hocke, K.: Atmosphere sounding by GPS radio occultation: First results from CHAMP, Geophys. Res. Lett., 28, 32633266, 2001.

Zou, C.-Z. and Wang, W.: Stability of the MSU-Derived Atmospheric Temperature Trend, J. Atmos. Ocean. Tech., 27, 19601971, doi:10.1175/2009JTECHA1333.1, 2009. 